\title{
The effect of merocel nasal packing use on cognitive functions
}

\author{
Fatih Arslan', Tuğba Kokulu Arslan ${ }^{2}$ \\ 1 Department of Otolaryngology, Head and Neck Surgery, Beytepe Murat Erdi Eker State Hospital, Ankara, Turkey. \\ 2 Anesthesiology and Reanimation Clinic, Ministry of Health Diskapı Research and Training Hospital, Ankara, Turkey. \\ Fatih Arslan, ORCID: 0000-0001-6030-7694 \\ Tuğba Kokulu Arslan, ORCID: 0000-0003-2909-2116
}

\begin{abstract}
Objective: It is known that the use of nasal packing has many disadvantages. The aim of this study was to investigate the effects of short-term nasal obstruction due to nasal packing on cognitive functions.

Methods: The study group consisted of 40 patients who had nasal congestion due to unilateral nasal septal deviation and for whom septoplasty was planned with a merocel pack to be used as a nasal pack at the end of surgery. All surgeries were performed under local anesthesia using 10 cc of jetocaine ampoule. Brief Symptom Inventory Test (BSI), Visual Analog Scale (VAS), Serial Digit Learning Test (SDL), Stroop Test, Visual Aural Digit Span Test (VADS) and P300 test were used to evaluate cognitive functions, symptoms of concentration difficulties and blunted affect both preoperatively and peroperatively before nasal pack removal.
\end{abstract}

Results: All symptoms showed significant per-operative (with a nasal pack in place) deterioration in all patients $(p<0.001)$ on the VAS. The mean per-operative SDL (16.34 \pm 5.77$)$, Stroop Test $(26.67 \pm 3.39)$, BSI $(22.25 \pm 11.95)$ and VADS $(21.13 \pm 3.44)$ scores showed significant deterioration compared with mean preoperative Stroop Test $(20.06 \pm 3.14)$, SDL $(22.38 \pm 4.34)$, VADS $(25.86 \pm 2.92)$ and BSI $(32.58 \pm 12.49)$ scores $(p<0.001)$. The peroperative and preoperative P300 latency and amplitude values showed a significant difference $(p<0.001)$.

Conclusion: The use of a nasal pack, which closes both nasal passages fully, such as a merocel pack, has negative effects on cognitive functions such as the ability to focus and maintain concentration.

Keywords: Nasal surgery, tampons, surgical, cognitive function, event-related potentials, p300. 


\section{Introduction}

One of the most important reasons for nasal obstruction is nasal septum deviation. It has been treated surgically for a long time and it is a common medical problem that exists in approximately one-third of the world population. ${ }^{[1]}$ Septoplasty is one of the most common surgeries in otolaryngology. Intranasal packs are widely used for bleeding control and postoperative nasal septum stabilization. ${ }^{[2]}$ After septal surgery, Doyle ${ }^{\mathrm{TM}}$ packs (Medtronic, Minneapolis, MN, USA), Rapid Rhino ${ }^{\mathrm{TM}}$ tampons (ArthroCareCorporation, Austin, TX, USA), Merocel®packs or gauze with vaseline or antibiotic pomade can be utilized as nasal packing. ${ }^{[3,4]}$

Merocel® (Medtronic Xomed, Jacksonville, FL, USA) nasal pack is widely preferred after surgery due to its ease of use and clinical efficacy for control of bleeding. ${ }^{[2,3]}$ The packs can usually be removed 24-48 hours after septal surgery. ${ }^{[3]}$ In addition to high availability and efficacy, the nasal pack is also well-known for causing headache, anxiety, eustachian dysfunction and poor quality of life during the period of use. ${ }^{[5,6]}$ Therefore, suture techniques, which may be an alternative to the use of packs, are being developed and pack types that are less likely to cause these complaints continue to be tested. ${ }^{[3,5-7]}$

Although it is known that the use of nasal packing has many disadvantages as mentioned above, no study has been conducted examining the effect on cognitive function and attention deficiency with standardized tests and objective methods. The aim of this study was to investigate the effects of short-term nasal obstruction due to nasal packing on cognitive functions.

\section{Materials and Methods}

This study was carried out in Gulhane Training and Research Hospital between March 2014 and January 2018, with the approval of the local ethics committee (Gülhane Military Medical Academy-Ankara/Turkey, 15.02.2013/1491-154-13/1648.4-424). The study group consisted of patients who had nasal congestion due to unilateral nasal septal deviation and for whom septoplasty was planned as a treatment. Patients with unilateral total or narrowing pathologies in both nasal passages (nasal septum deviation and/or turbinate hypertrophy) were excluded from the study since it was thought that possible quality of life and sleep disturbance and consequent cognitive function and attention disorders might be present. Particular attention was paid that patients who were to be included in the study had complaints of nasal breathing and that this was caused by a unilateral septum deviation of the nasal passage that was not a total narrowing. Exclusion criteria were the following: patients younger than 18 years old, acute sinusitis, nasal anatomical deformity causing nasal congestion, nasal tumor, vasomotor rhinitis or allergic rhinitis confirmed by skin tests, nasal congestion caused by systemic disease such as hypothyroidism, poor hearing, mental or neuropsychological disease or using psychological drugs. All patients who were registered in this study had no awakening with choking sensations or witnessed apneas. Moreover, patients with obstructive sleep apnea syndrome confirmed by polysomnography were excluded.

Nasal septum deviation was evaluated using anterior rhinoscopy and nasal endoscopy in all patients. Preoperative blunted affect and impaired concentration symptoms were rated using a $10 \mathrm{~cm}$ visual analog scale form. Stroop test, Visual Aural Digit Span Test B (VADS-B), Brief Symptom Inventory Test (BSI) and Serial Digit Learning Tests (SDL) were then conducted in the department of psychiatry to evaluate cognitive functions. The patients were supposed to have stopped drugs affecting attention a week before the tests. They were asked to have a nice, relaxing sleep the day before the tests. They had no significant problems in their lives on the test day and they had not taken narcotic drugs or alcohol for a day before the test. The training period was at least 8 years in duration and the upper age limit was 54 years to allow evaluation and application of neuropsychiatric tests.

The VADS-B was used to assess short-term memory and was capacity-limited. The Stroop Test TBAG form was used to evaluate 'sustainability and intensification of attention', 'stopping and suppressing of inappropriate warning and reaction tendency', and 'ability of resistance towards disruptive stimulus'. The BSI Test, which is a multidimensional symptom screening scale used to detect various medical and psychological diseases, was applied to individuals while situated alone in an adequately lit and silent room. SDL was performed to measure attention, memory and learning ability. All tests were performed as described in the literature. ${ }^{[8]}$

Event related auditory evoked potentials (P300) were recorded with an EMG device (4-channel Natus brand Synergy model -2008 USA) in a bright and silent room in the Neurophysiology Laboratory of the Neurology Department. Sleep Sense gold electrodes with Ten20 Conductive neurodiagnostic electrode posts were used. The active electrodes were placed on $\mathrm{Fz}, \mathrm{Cz}, \mathrm{C} 3$ and $\mathrm{C} 4$ 
points according to the international $10-20$ system and the recordings were done by taking both mastoid areas as reference points. Impedances were held lower than $5 \mathrm{k} \Omega$. Toward both ears, auditory stimuli were given at $60 \mathrm{~dB}$ higher than the equal hearing value. The frequency of the target frequency was $2800 \mathrm{~Hz}$, while the untargeted stimulus was determined as $1800 \mathrm{~Hz}$. The stimulus frequency was determined as $0.7 / \mathrm{s}$. Target and untargeted sounds were introduced after informing the patients about the test. The patient was requested to count the target sounds, which made up twenty percent of the randomly occurring total sounds. The recording was continued until 40 target sounds were recognized. The recordings were repeated twice. $\mathrm{Cz}$ recording points were assessed while analyzing the data.

All patients underwent a septoplasty with a classic Kilian incision. All surgeries were performed under local anesthesia using $10 \mathrm{cc}$ of jetocaine ampoule (each $1 \mathrm{ml}$ contains $20 \mathrm{mg}$ lidocaine hydrochloride and $0.0125 \mathrm{mg}$ epinephrine base) (Adeka llaç, Samsun, Turkey). At the end of the surgery, an $8 \mathrm{~cm}$ standard Merocel@ pack without airway (Medtronic Xomed, Jacksonville, FL, USA) was placed into both nasal cavities of each patient. Postoperative 1 gr amoxicillin-clavulanic acid was administered orally and naproxen sodium was prescribed $550 \mathrm{mg}$ twice daily to all patients. In the per-operative period, before the nasal pack was removed at the end of day 2 (before nasal packing removal, about 48 hours after the operation), all tests were repeated and the results were compared. SPSS for Win. Ver. 15.0 (SPSS Inc., Chicago, IL., USA) was used for data analysis. Wilcoxon test and Spearman correlation analysis test were used for data comparisons. Statistically, $\mathrm{p}<0.05$ was accepted as a significant value.

\section{Results}

A total of 40 patients [38 (95\%) men and $2(5 \%)$ women] between 21 and 26 years old (mean age $22.83 \pm 2.26$ years) were included in the study. In the evaluation performed in the per-operative period (in the presence of a nasal pack), both impaired concentration and blunted effect were significantly increased compared to preoperative measurements $(\mathrm{p}<0.001)$ (Table 1). The mean preoperative Stroop test score was $20.06 \pm 3.14$, whereas the peroperative mean Stroop test score was $26.67 \pm 3.39$. The mean preoperative SDL test score was $22.38 \pm 4.34$, whereas the peroperative mean SDL test score was $16.34 \pm 5.77$. The mean preoperative VADS-B test score was $25.86 \pm 2.92$, whereas the peroperative mean VADS-B test score was $21.13 \pm 3.44$. The mean preoperative BSI test score was $32.58 \pm 12.49$, whereas the peroperative mean VADS-B test score was $22.25 \pm 11.95$. In all of the tests and in all patients, a significant deterioration was detected in the peroperative measurements compared to preoperative measurements. $(\mathrm{p}<0.001)$ (Table 2).

The mean preoperative latency of P300 was $321.66 \pm 14.30$, whereas the peroperative value was $354.41 \pm 19.36$, and the mean preoperative amplitude of $\mathrm{P} 300$ was $16.67 \pm 5.38$, whereas the peroperative value was $11.78 \pm 4.51$. The preoperative and peroperative latency of P300 values and amplitudes of $\mathrm{P} 300$ values showed a significant difference $(\mathrm{p}<0.001)$ (Table 1$)$.

\section{Discussion}

Various types of nasal packing and/or septal sutures can be used to help wound recovery and prevent complications such as adhesion of nasal cavities and septal hematoma and to stabilize the newly created septum at the end of surgical procedures on the nasal septum. ${ }^{[9,10]}$ However, nasal packing decreases postoperative patient comfort significantly, causes pain, anxiety and a feeling of pressure on the face. ${ }^{[2,11]}$ The pain and discomfort due to nasal packing gradually increase during the time that it remains in the nose, and become severe while withdrawing the packing material. ${ }^{[12]}$ To reduce the related pain and discomfort, many different

\begin{tabular}{|c|c|c|c|}
\hline$n=40$ & Preoperative & Peroperative & $p$ value \\
\hline Latency (ms) & $321.66 \pm 14.30$ & $354.41 \pm 19.36$ & $<0.001$ \\
\hline Amplitude $(\mu \mathrm{V})$ & $16.67 \pm 5.38$ & $11.78 \pm 4.51$ & $<0.001$ \\
\hline $\begin{array}{l}\text { Diffuculty in concentration } \\
\text { (mean } \pm \text { SD) }\end{array}$ & $1.25 \pm 0.82$ & $7.88 \pm 2.26$ & $<0.001$ \\
\hline Blunted affect (mean \pm SD) & $1.16 \pm 0.33$ & $6.16 \pm 2.17$ & $<0.001$ \\
\hline
\end{tabular}

$\mu \mathrm{V}$ : microvolt, ms: millisecond, $\mathrm{n}$ : number of patients, SD: standart deviation. 


\begin{tabular}{|c|c|c|c|c|}
\hline$n=40$ & $\begin{array}{l}\text { Peroperative test points } \\
\text { (patients number) }\end{array}$ & Preoperative score mean $\pm S D$ & Peroperative score mean \pm SD & $p$ value \\
\hline & Deterioration & & & \\
\hline Stroop TBAG & $40 / 40(\% 100)$ & $20.06 \pm 3.14$ & $26.67 \pm 3.39$ & $<0.001$ \\
\hline SDL Test & $40 / 40(\% 100))$ & $22.38 \pm 4.34$ & $16.34 \pm 5.77$ & $<0.001$ \\
\hline VADS -B & $40 / 40(\% 100)$ & $25.86 \pm 2.92$ & $21.13 \pm 3.44$ & $<0.001$ \\
\hline BSI & $40 / 40(\% 100)$ & $32.58 \pm 12.49$ & $22.25 \pm 11.95$ & $<0.001$ \\
\hline
\end{tabular}

BSI: Brief Symptom Inventory Test, SD: standart deviation, SDL: Serial Digit Learning Test, Stroop TBAG: Stroop Test for Basic Science Research Group, VADS-B: Visual Aural Digit Span Test B.

types of nasal packing have been developed although it has not been possible to completely eliminate the effects.

Since the adverse effects associated with the above-mentioned packs are well defined, alternative methods to the use of packs after septal surgeries are being developed. ${ }^{[13,14]}$ However, in some cases where it is known that packings must be used, alternative packs are used that may have lower adverse effects compared to the merocel packs. ${ }^{[15,16]}$ In the current situation, symptoms such as a feeling of pressure on the face, pain, restlessness, lack of attention, focusing and quality of life problems can be observed by most ENT surgeons. Even before the surgery and at the first doctor visit after surgery, patients often ask when packs are going to be removed before even asking about the surgery, since this situation is enough to express the feeling of discomfort caused by the packing.

In particular, patients state that they have sleep disorders caused by the packing. Problems of attention deficit, inability to stay in place, impatience, restlessness and poor focusing that we observed are caused by sleep disorders and can be clearly seen in patients, especially between 3648 hours of pack duration. One of the most common answers given by patients when asked how they are is: "It is very difficult to live with the packings and I can't get the taste and pleasure of anything I eat or drink." This answer clearly shows the emotional bluntness and anhedonia.

While the presence of some of the aforementioned symptoms is clearly established by studies, there is no literature examining the presence of attention deficit, focusing difficulty, emotional bluntness and anhedonia symptoms. However, as each surgeon knows, patients do a lot of work that requires attention and focus (for example car use, home-office employee accountant or people who deal with monetary account work) in the period until the nasal pack is removed. Particularly in the part of the process where the packs remain in the nose, it is clear how dangerous and risky it is to do some of these tasks, and this may cause situations that are difficult to compensate. We aimed to elucidate this situation with objective and subjective tests, to strengthen the hand of physicians, and to provide results that could be taken as a reference when possible undesirable problems are encountered. The STROOP TBAG form was used to measure response inhibition, focused attention, disturbance impact resistance and information processing speed, whereas short-term memory, sensory-motor integration and sequencing was measured by VADS-B. Shortterm memory and learning were evaluated using the SDL. We also aimed to demonstrate and compare the symptoms of concentration difficulty and emotional blunting using VAS. In all of the results, tests in the presence of pack clearly showed that there was a significant deterioration compared to the preoperative test results.

In our study, we used the P300 test, which is one of the most frequently used objective tests in this area, in order to assess the loss of attention, lack of concentration and other cognitive functions caused by nasal packing. P300, which is widely used to determine cognitive dysfunction in many neuropsychiatric diseases, is a valuable test for evaluating personal cognitive processes such as attention, decision-making, stimulation evaluation time, memory and personal cognitive processes such as the process of information entering the central nervous system. Amplitude values of P300 display attention and cognitive function related to the importance of the stimulus and expectation, while latency demonstrates the evaluation time of responses to the target stimulus. Disturbed cognitive functions 
cause prolonged latency and decreased amplitude..$^{[8]}$ This test was previously used to evaluate cognitive functions in patients with a long-term nasal obstruction due to nasal polyps, and it was found that long-term nasal obstruction results in negative effects on cognitive function. In our study, the apparent prolongation of the P300 latency and marked reduction in amplitudes in the presence of nasal pack showed that the presence of nasal pack caused a very clear and objective deterioration in cognitive functions.

\section{Conclusions}

Findings from this study revealed that nasal packing caused significant deterioration in cognitive functions such as attention deficit and concentration difficulty focus in patients. It also impaired quality of life and created emotional bluntness. Also, the results indicated that patients should not do activities that would require concentration and focus in the presence of nasal packs, and that written informed consent should be obtained if necessary. In addition, this study has paved the way and has revealed the necessity for new studies evaluating the relationship between cognitive function and alternative packing types other than merocel packs, as well as suture techniques which are an alternative to nasal packing techniques.
Acknowledgments: We thank Psychologist Gökçe ÖZER and Serdar TAŞDEMiR (neurologist, M.D.) for her contribution to our study by measuring and evaluating cognitive fonctions.

Ethics Committee Approval: This study was carried out with the approval of the local ethics committee (Gülhane Military Medical AcademyAnkara/Turkey, 15.02.2013/1491-154-13/1648.4-424).

Informed Consent: Informed consent was obtained from all individual participants included in the study.

Author Contributions: Designing the study F.A.; Collecting the data - F.A.; Analysing the data - T.K.A.; Writing the manuscript - F.A.; Confirming the accuracy of the data and the analyses T.K.A.

Conflict of Interest: The authors have no conflicts of interest to declare.

Financial Disclosure: The authors declared that this study has received no financial support. 


\section{References}

1. Arslan F, Kokulu Arslan T. A Very Important Warning for Septoplasty under Local and Local Anesthesia with Sedation. J Anest \& Inten Care Med 2018;7:1-2.

2. Şahin C, İmer Aras H. Influence of nasal pack removal on patients' anxiety after septoplasty. Kulak Burun Bogaz Ihtis Derg 2015;25:266-70.

3. Acıoğlu E, Edizer DT, Yiğit Ö, Onur F, Alkan Z. Nasal septal packing: which one? Eur Arch Otorhinolaryngol 2012;269:1777-81.

4. Hesham A, Ghali A. Rapid Rhino versus Merocel nasal packs in septal surgery. J Laryngol Otol 2011;125:1244-6.

5. Özkırış M, Kapusuz Z, Saydam L. Comparison of nasal packs with transseptal suturing after nasal septal surgery. Am J Otolaryngol 2013;34:30811.

6. Durmaz A. Nasal Septal Chain Suture: a New Suturing Technique. J Craniofac Surg 2017;28:220-4.

7. Durmaz A. A Modification to the Nasal Septal Chain Suture Which Improves Its Application. J Craniofac Surg 2018;29:502-5.

8. Arslan F, Tasdemir S, Durmaz A, Tosun F. The effect of nasal polyposis related nasal obstruction on cognitive functions. Cogn Neurodyn 2018;12:385-90.

9. Dobratz EJ, Park SS. Septoplasty pearls. Otolaryngol Clin N Am 2009;42:527-37.
10. Plasencia DP, Falcón JC, Barreiro SB, Bocanegra-Pérez MS, Barrero MV, Macías ÁR. Transeptal suturing - a cost-efficient alternative for nasal packing in septal surgery. Braz J Otorhinolaryngol 2016;82:310-3.

11. Cukurova I, Cetinkaya EA, Mercan GC, Demirhan E, Gumussoy M. Retrospective analysis of 697 septoplasty surgery cases: packing versus trans-septal suturing method. Acta Otorhinolaryngol Ital 2012;32:111-4.

12. Dubin MR, Pletcher SD. Postoperative packing after septoplasty: is it necessary? Otolaryngol Clin North Am 2009;42:279-85.

13. Dalgic A, Is A, Dinc ME, Ulusoy S, Avinçsal MÖ, Kulekci M. The Effects of Nasal Packing and Transseptal Suturing After Septoplasty on Olfactory Function, Patient Comfort, and Mucociliary Clearance. J Craniofac Surg 2016;27:487-90.

14. Özbal Koç AE, Türkoğlu Babakurban S, Kibar SS, Büyüklü F. A comparative study on nasal packing after septoplasty: does it matter in terms of patient comfort, bleeding, and crust or synechia formation? Kulak Burun Bogaz Ihtis Derg 2016;26:152-8.

15. Bingöl F, Budak A, Şimşek E, Kılıç K, Bingöl BÖ. Comparison of Early-period Results of Nasal Splint and Merocel Nasal Packs in Septoplasty. Turk Arch Otorhinolaryngol 2017;55:136-9.

16. Abu Eta R, Eviatar E, Pitaro J, Gavriel H. Post-turbinectomy nasal packing with Merocel versus glove finger Merocel: A prospective, randomized, controlled trial. Ear Nose Throat J 2018;97:64-8.

This is an open access article distributed under the terms of the Creative Commons Attribution-NonCommercial-NoDerivs 3.0 Unported (CC BY- NC-ND3.0) Licence (http://creativecommons.org/licenses/by-nc-nd/3.0/) which permits unrestricted noncommercial use, distribution, and reproduction in any medium, provided the original work is properly cited.

Please cite this article as: Arslan F, Kokulu Arslan T. The effect of merocel nasal packing use on cognitive functions. ENT Updates 2020;10(1):265-270. 